\title{
The role of the CCR1 receptor in the inflammatory response to tobacco smoke in a mouse model
}

\author{
Per-Ola Önnervik $\cdot$ Maria Lindahl $\cdot$ Naila Svitacheva \\ Martin Stämpfli $\cdot$ Kerstin Thim • Amir Smailagic • \\ Robert Virtala $\cdot$ John D. Taylor
}

Received: 25 August 2009/Revised: 19 March 2010/ Accepted: 22 March 2010/Published online: 13 April 2010

(C) The Author(s) 2010. This article is published with open access at Springerlink.com

\begin{abstract}
Objective The aim was to create pathological changes in mice relevant to human smoke exposure that can be used to further understand the mechanisms and pathology of smoke-induced inflammatory disease.

Methods Mice were exposed to tobacco smoke or lipopolysaccharide (LPS) to generate an inflammatory infiltrate within the lungs.

Results Tobacco smoke exposure over a 4 day period led to neutrophilia in the lungs of BALB/c mice. Within the inflammatory exudates, significant changes were also seen in protein levels of IL-1B, IL-6, MIP-2, KC (IL-8) and TIMP-1 as measured by ELISA. Further protein changes, as measured via multiplex analysis revealed increased levels of MMP-9, MDC, LIF and MCP-1, amongst other mediators. Major changes in whole lung tissue gene expression patterns were observed. The neutrophilia seen after smoke exposure was steroid-insensitive, relative to doses of steroid needed to reduce LPS-driven neutrophilia in controls. This exposes pathological switches that are changed upon exposure to tobacco smoke, rendering steroids less effective under these conditions. Challenge of chemokine receptor type 1 (CCR1) KO mice in the tobacco
\end{abstract}

Responsible Editor: M. Parnham.

P.-O. Önnervik · M. Lindahl · N. Svitacheva · M. Stämpfli ·

K. Thim · A. Smailagic · R. Virtala · J. D. Taylor $(\bowtie)$

Integrative Pharmacology, Department of Biosciences,

AstraZeneca R\&D Lund, Respiratory and Inflammation

Research Area, 22187 Lund, Sweden

e-mail: john.d.taylor@astrazeneca.com

M. Stämpfli

Department of Pathology and Molecular Medicine,

Centre for Gene Therapeutics, McMaster University,

Hamilton, ON L8N 3Z5, Canada smoke model showed that lack of this gene protected the mice from smoke-induced inflammation.

Conclusions This suggests the CCR1 receptor has a key role in the pathogenesis of smoke-induced inflammation.

Keywords Chronic obstructive pulmonary disease . Tobacco smoke induced inflammation - Steroid . $\mathrm{C}$ chemokine receptor 1

$\begin{array}{ll}\text { Abbreviations } \\ \text { BAL } & \text { Bronchoalveolar lavage } \\ \text { CCR1 } & \text { Chemokine receptor type 1 } \\ \text { ELISA } & \text { Enzyme linked immune sorbent assay } \\ \text { IL-1 } & \text { Interleukin 1 } \\ \text { IL-6 } & \text { Interleukin 6 } \\ \text { IL-8 } & \text { Interleukin 8 } \\ \text { KC } & \text { Keratinocyte chemoattractant } \\ \text { KO } & \text { Knock out } \\ \text { FP } & \text { Fluticasone propionate } \\ \text { LIF } & \text { Leukemia inhibitory factor } \\ \text { MCP-3 } & \text { Monocyte-specific chemokine 3 } \\ \text { MIP-1 } & \text { Macrophage inflammatory protein 1 } \\ \text { MIP-2 } & \text { Macrophage inflammatory protein 2 } \\ \text { MMP-9 } & \text { Matrix metalloproteinase 9 } \\ \text { RSV } & \text { Respiratory syncytial virus } \\ \text { TIMP1 } & \text { Tissue inhibitors of metalloproteinase 1 } \\ \text { TNF } & \text { Tumour necrosis factor } \\ \text { TS } & \text { Tobacco smoke }\end{array}$

\section{Introduction}

Chronic obstructive pulmonary disease (COPD) is a major cause of death and morbidity in the Western world [1]. It is 
becoming increasingly common and will soon be the third leading cause of death in the world. COPD is increasing in developing countries [2]. The main causative agent in COPD is cigarette smoke [3]. In addition, a genetic component is involved in the development of COPD [4]. Treatments for COPD include both inhaled corticosteroids (ICS), Beta2 agonists, muscarinic receptor antagonists and combinations of these agents [5].

We have established a mouse model of inflammation which is triggered by tobacco smoke. This model is being used to understand the link between pathological events in the inflammatory model and human disease. The model can be used to test target mechanisms for use as potential new anti-inflammatory treatments and to understand the pharmacology of the inhibitors of such mechanisms. We have assessed the activity of steroids in the model and found steroids to be relatively inactive in comparison to steroid activity in a separate lipopolysaccharide (LPS) driven inflammatory model. Finally, we show the effects of CCR1 transgenic $(\mathrm{KO})$ mice on the inflammatory response.

The model we describe is a new robust model and for an in vivo application is of reasonably high throughput. We hope the model can serve as a platform for the testing of other mechanisms and hypotheses to further understand the pathobiology of cigarette smoke-induced inflammation. This could also include the addition of other components to the protocol; such studies have already been carried out with the addition of bacteria to a 4 day smoke exposure [6].

\section{Materials and methods}

\section{Animals}

Female BALB/c mice (weighing 18-22 g) were purchased from Taconic Europe A/S (Denmark), housed 4-6 per cage and allowed to acclimatize for 1 week before experiments. Animals were provided with food, R70 pellets (Lantmännen, Sweden), and water ad libidum. Their body weights were measured prior to first exposure and termination.

CCR1 KO mice (weighing 18-22 g) backcrossed to C57BL/6 for ten generations were bought from the Children's Medical Center Corporation, Boston, MA, USA. Age matched C57BL/6 mice were used as controls. Female mice were used in all experiments.

Animals were handled in conformity with standards established by Council of Europe ETS123 AppA, Swedish legislation and AstraZeneca global internal standards.

Tobacco smoke exposure

Mice were exposed to cigarette smoke using a whole body smoke exposure unit SIU48 (PromechLab AB,
Vintrie, Sweden). Up to 64 mice were placed in a sealed exposure chamber, divided into separate chambers and exposed to mainstream tobacco smoke or room air (control mice). Smoke was generated from 1R3F research cigarettes (Tobacco and Health Research Institute, University of Kentucky) with filters removed. Smoke was drawn into the box with a vacuum flow that was aligned to 16 puffs per cigarette. Air was drawn into the box after each puff, and the control unit automatically cycled the opening and closing of air and smoke inlets (5 sec air and $10 \mathrm{sec}$ smoke). Side stream smoke was removed via exhaust. Animals were exposed to 12 cigarettes, twice daily, for $1,2,3,4$, or 9 days. There was a $5 \mathrm{~h}$ interval between the exposures. The SIU48 allows for monitoring of smoke input in real time to ensure consistency between exposures. Terminations and analysis were carried out in each case $16 \mathrm{~h}$ after the last smoke exposure.

The exposure system and methods are identical to that already described and published in Gashler et al. [6]. Cotinine levels were measured by ELISA (Bio-Quant, San Diego, CA, USA) in the blood of mice after 4 days of smoke exposure. In all mice levels of cotinine were approximately $350 \mathrm{ng} / \mathrm{ml}$. In addition, carboxyhaemoglobin levels were measured by spectrometry and were approximately $7 \%$ after smoke exposure.

\section{LPS exposure}

Female BALB/c mice (weighing 18-22 g) were used. Nonanaesthetised mice were placed into a ventilated chamber, that was directly connected to a Pari LC ${ }^{\circledR}$ JetStar nebuliser (PARI Respiratory Equipment, Inc., Midlothian, VA, USA), and exposed either to $1 \mathrm{mg} / \mathrm{ml} P$. aeruginosaderived LPS (L9143, Sigma-Aldrich) or to the vehicle $(0.9 \% \mathrm{NaCl})$ for $10 \mathrm{~min}$.

\section{Bronchoalveolar lavage}

Mice were anaesthetised by an interperotineal (i.p.) injection of sodium pentobarbital $(60 \mathrm{mg} / \mathrm{kg})$ either $16 \mathrm{~h}$ after the last smoke exposure or $24 \mathrm{~h}$ after LPS challenge. After semi-excision of the trachea, a plastic catheter was inserted, and the bronchoalveolar lavage (BAL) fluid was collected by passive/gravity flow of phosphate buffered saline $(\mathrm{PBS})(2 \mathrm{ml} \times 2$ times; a $2 \mathrm{ml}$ syringe placed at $23 \mathrm{~cm}$ height) into the lungs. Retrieved fluid, kept on ice at $4^{\circ} \mathrm{C}$ from both washes was pooled and centrifuged $\left(1,200 \mathrm{rpm} \times 10 \mathrm{~min}, 4^{\circ} \mathrm{C}\right)$. The supernatant was aliquoted and saved at $-70^{\circ} \mathrm{C}$ for mediator analysis; the cell pellet was resuspended in $0.25 \mathrm{ml} \mathrm{PBS}$ and maintained at $4^{\circ} \mathrm{C}$ until cell determination. 
Cell count and differentiation

Total cell number in BAL was determined using a semi automatic cell counter Sysmex F-800. Differential cell counts were performed using standard morphological criteria on May-Grünwald and Giemsa (Merck) stained cytospins $(50,000$ cells/slide, $500 \mathrm{rpm} \times 3 \mathrm{~min}$, Shandon CytoSpin 3 cytocentrifuge). At least 200 cells were counted per cytospin. Leukocyte numbers were determined by multiplying the percentage of each leukocyte subpopulation with the total number of cells for each sample and expressed as cell number/sample.

Mediator measurements and multiplex analysis

Mediators (KC, MIP-1 $\alpha$, MIP-2, IL-1 $\beta$, IL-6, TIMP-1) were determined using ELISA kits (R\&D System, USA) according to the manufacturer's instructions. In some studies BAL fluid samples were sent to Rules Based Medicine (Texas, USA) for multiplex analysis.

Treatment with compounds

The mice were anaesthetised with an isoflurane mixture $\left(\mathrm{N}_{2} \mathrm{O}: \mathrm{O}_{2} ; 1.2: 1.4\right.$ and $4 \%$ isoflurane), put in a supine position with $30^{\circ}-40^{\circ}$ angle and intratracheally (i.t.) instilled either with vehicle or fluticasone propionate (FP) in a volume of $1 \mathrm{ml} / \mathrm{kg} 1 \mathrm{~h}$ prior to LPS or tobacco smoke exposure. The topical instillations were performed using a modified metal cannula with a bulb-formed top.

\section{Statistical analysis}

Data are expressed as mean \pm SEM. Statistical analysis was performed using Student's $t$ test for samples with unequal variances. $P$ values $<0.05$ were considered as statistically significant.

\section{Gene expression analysis}

Expression levels of more than 39,000 transcripts were measured in whole lung tissue from mice exposed to fresh air $(n=10)$ or cigarette smoke $(n=10)$ using Affymetrix GeneChip $^{\circledR}$ Mouse Expression Arrays 430A and 430B (Affymetrix, Santa Clara, CA, USA). Whole lung tissue was homogenized using a dismembrator (Mikro-Dismembrator U, B. Braun Biotech International, PA, USA) and RNA isolated according to the TRIzol ${ }^{\circledR}$ protocol (Invitrogen, Carlsbad, CA, USA) with an additional purification using RNeasy columns (Qiagen, Hilden, Germany). Total RNA was measured spectrophotometrically and the quality assessed by visualization of ribosomal RNA bands on $1 \%$ agarose gels. Ten micrograms of total RNA from each sample was used to generate hybridisation probes according to the Affymetrix GeneChip Expression Analysis Technical Manual (Affymetrix). Double-stranded cDNA was synthesised (Invitrogen) and subsequently in vitro transcribed in the presence of biotinylated nucleotides using an Enzo BioArray ${ }^{\mathrm{TM}}$ HighYield ${ }^{\mathrm{TM}}$ RNA Transcript Labelling Kit (Enzo Life Sciences, Inc., Farmingdale, NY, USA). Fifteen micrograms of fragmented cRNA were hybridised to each array. Hybridisation, washing and staining of the arrays were performed according to the instructions provided by Affymetrix. The GCOS software from Affymetrix was used to generate transcript expression level values, signals, and corresponding present call values as measures of the certainty of detection. Group comparisons between the fresh air and cigarette smoke treated groups were made using a modified $t$ test, Samroc [7] and overall differences between samples analysed with Principal Component Analysis in SIMCA-P + (Umetrics AB, Umeå, Sweden) and visualised in Spotfire ${ }^{\circledR}$ DecisionSite ${ }^{\circledR}$ (TIBCO Spotfire Inc., Gothenburg, Sweden).

\section{Results}

Tobacco smoke exposure results in an inflammatory cell based influx

The whole body smoke exposure system was developed in collaboration with ProMech (Malmö, Sweden) and enables the exposure of up to 60 animals at a time. The smoke exposure was carried out within a sealed unit where the animals were placed and were free to move. The smoke was allowed to flow through the cabinet and there was a continual flow of air through the exposure area. The smoke exposure system is identical to the one used in a previous publication [6]. The same system was used for air-exposed control animals but no tobacco smoke was in the chamber.

Exposure for 50 min two times a day produced a robust cell influx as measured in the BAL (Fig. 1). Cell influx peaked at day 4 , although inflammation was also observed when animals were exposed for 9 days. The inflammatory cell influx was dominated by neutrophils. Other cell types were seen in the BAL in smaller numbers, including macrophages. Experiments where animals were exposed only once per day produced little inflammation (data not shown).

Airway inflammation is characterised by a range of inflammatory mediators

Cytokine mediators were measured in the BAL and these were correlated with the inflammatory cell influx (Fig. 2). 


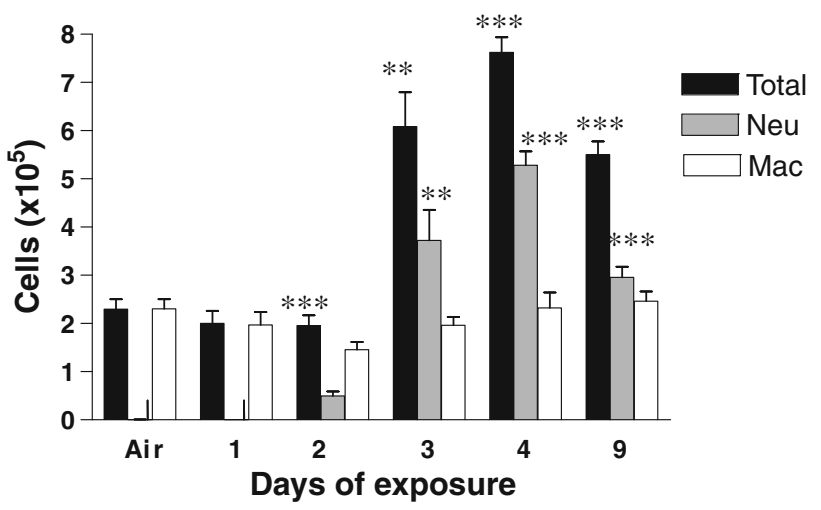

Fig. 1 Cellular infiltrate in BAL following TS exposure. BALB/c mice (groups of 8) were exposed to either air or TS twice a day for 50 min for $1,2,3,4$, or 9 days, then were terminated and cells counted from BAL. Total cells are shown (black columns) and neutrophils (grey columns) and macrophages (clear columns). Statistically significant differences in response to air controls are shown $* P<0.05, * * P<0.01, * * * P<0.001$. The data for the air control groups for each day have been pooled and shown as "air"
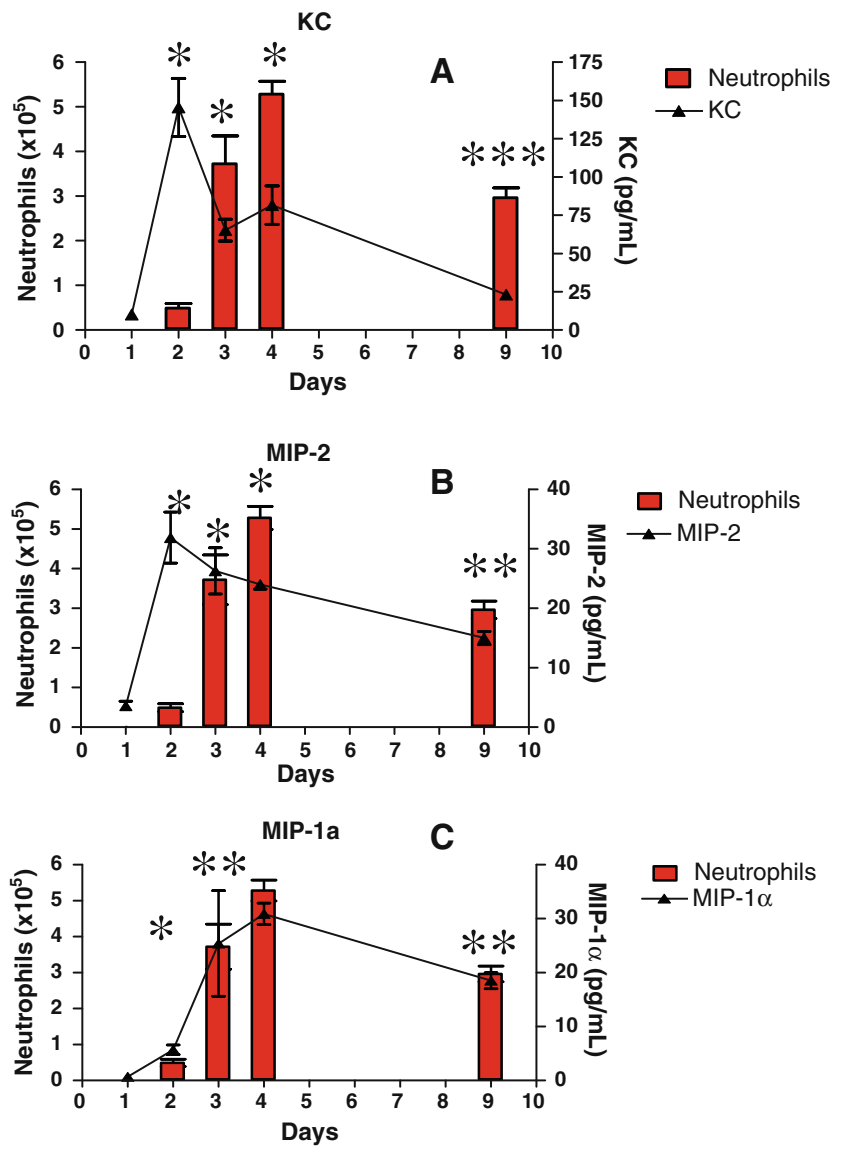

Fig. 2 Time course of inflammatory infiltration into BAL. BALB/c mice (groups of 8) were exposed to TS for between 1 and 9 days for $50 \mathrm{~min}$, twice a day. Red columns show the presence of neutrophils at the various time points (which are identical a-f). The lines show the presence of cytokines present within the BAL at various time points.
The levels of $\mathrm{KC}$ peaked before the peak of inflammatory neutrophils. Further temporal analysis of mediator levels versus neutrophilia also showed the presence of IL- $1 \beta$, IL-6, MIP-1 $\alpha$, MIP-2, and TIMP-1 with respect to time. IL-1 $\beta$ levels and MIP- $1 \alpha$ levels peaked at the same time as neutrophil levels (Fig. 2). Using Rules Based Medicine's analysis, we further characterised the protein infiltrate and saw that a number of mediators increased in the BAL following TS exposure. Proteins showing the most increase in presence in the BAL included MMP-9, TIMP-1, MCP-1 and MIP-1 (Table 1). At no time point could any TNF $\alpha$ levels be detected within the BAL.

After TS exposure substantial changes in the expression of genes within the lung are observed

Gene expression changes in the lung were determined using Affymetrix GeneChip ${ }^{\circledR}$ microarrays. TS treatment caused an increase of 685 probe sets and a decrease of 586
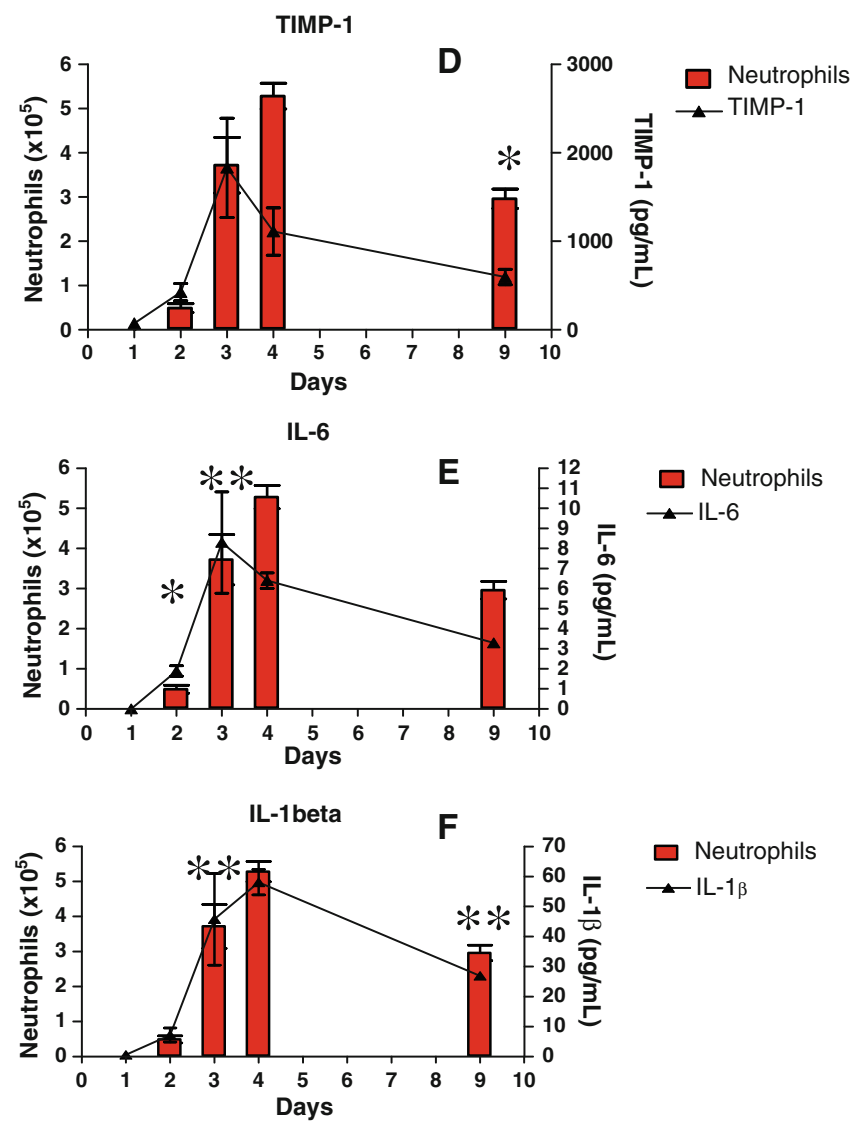

Statistically significant differences in response to air controls are shown $* P<0.05, * * P<0.01, * * * P<0.001$. The different cytokines measured are as follows: a KC, b MIP-2, c MIP-1a, d TIMP-1, e IL6, f IL-1 beta 
Table 1 Gene expression and mediator changes within BAL

\begin{tabular}{lll}
\hline Mediator & mRNA ratio smoke/air & Protein ratio smoke/air \\
\hline IL-1 $\beta$ & $1.9 * * *$ & $2.9 * * *$ \\
KC & $10^{* * *}$ & $5.0^{* *}$ \\
MCP-1 & $5.5 * * *$ & $9.7 * * *$ \\
MMP-9 & $1.2^{*}$ & $7.1^{*}$ \\
TIMP-1 & $5.3^{* * *}$ & $16^{*}$
\end{tabular}

IL-1 $\beta, \mathrm{KC}, \mathrm{MCP}-1$, MMP-9 and TIMP-1 mRNA and protein levels in samples from cigarette smoke treated animals (tobacco smoke for 4 days) relative to samples from animals receiving fresh air (air for 4 days)

$* P<0.05 ; * * P<0.01 ; * * * P<0.001$

probe sets out of 20,344 probe sets detected in at least $20 \%$ of the samples, using a group comparison $P$ value below 0.001 as cut-off. Among the most highly upregulated genes after TS treatment were the acute phase protein serum amyloid A-3, Saa3 $(27 \times$ increase, $P$ value $=0.000004)$, chemokine (C-X-C motif) ligand 5, CXCL5 (26× increase, $P$ value $=0.0002)$, NADPH oxidase organiser 1 , Noxo1 $(25 \times$ increase, $P$ value $=0.00001)$ and matrix metallopeptidase 12 , MMP-12 $(10 \times$ increase, $P$ value $=0.00001)$.
Changes in BAL fluid protein levels for IL-1 $\beta$, KC, MCP-1, MMP-9 and TIMP-1 were also seen at the transcriptional level in whole lungs (Table 1).

Response to TS is insensitive to steroids relative to an LPS model

We wished to compare the sensitivity of the inflammatory response to TS with another inflammatory model, so we also used an LPS mouse model to generate a BAL specific neutrophilia (Fig. 3b). We included groups that had been exposed to LPS and treated with different concentrations of a steroid, FP. It can be seen that FP was able to significantly reduce the LPS-driven inflammation. We carried out an analogous experiment in the TS-driven inflammatory model (Fig. 3b). Here, even though the same doses of FP were used, no significant inhibition of the TS-driven neutrophilia could be observed. No other cell types were significantly inhibited by treatment with FP (Fig. 3a). In addition, it can be seen that the levels of neutrophilia in the BAL were lower in the TS-driven system than in the LPSdriven model, and still no significant inhibition with FP could be observed.

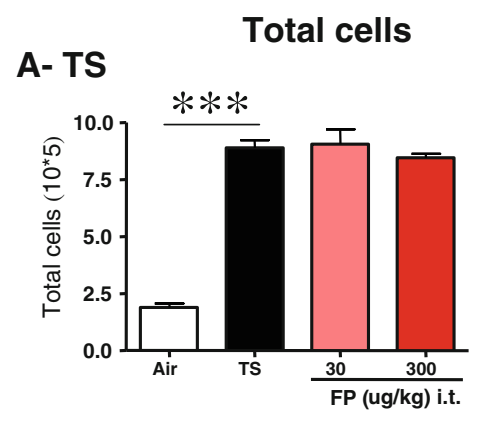

Total cells

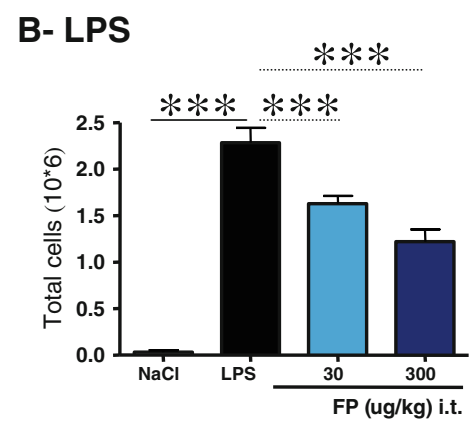

Fig. 3 Sensitivity of tobacco smoke model to steroids relative to an analogous LPS model. a Sensitivity of the TS-induced inflammation to steroids. Four groups of BALB/c mice ( 8 mice per group) were exposed to air, tobacco smoke, tobacco smoke plus $30 \mu \mathrm{g} / \mathrm{kg}$ of FP, tobacco smoke plus $300 \mu \mathrm{g} / \mathrm{kg}$ FP. The cellular response in BAL is shown, reflecting total cells, macrophages and neutrophils. Statistically significant differences between groups are shown as $* P<0.05$,
Macrophages

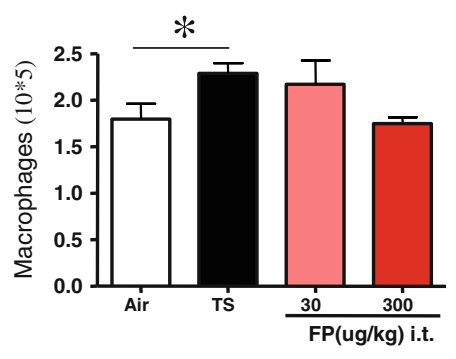

Macrophages

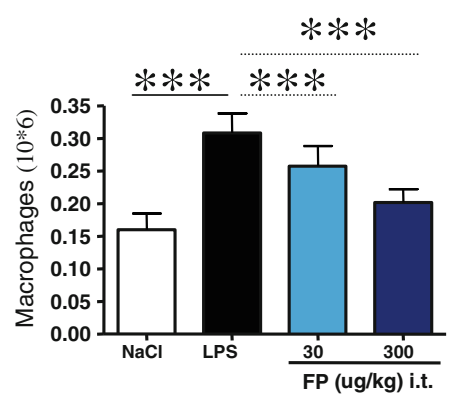

Neutrophils

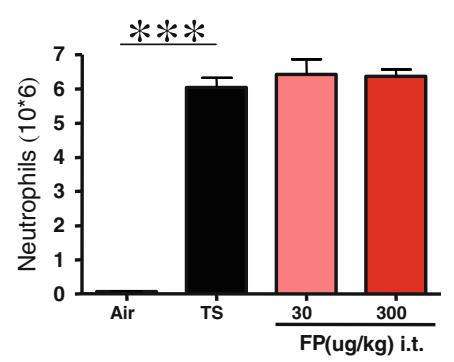

Neutrophils

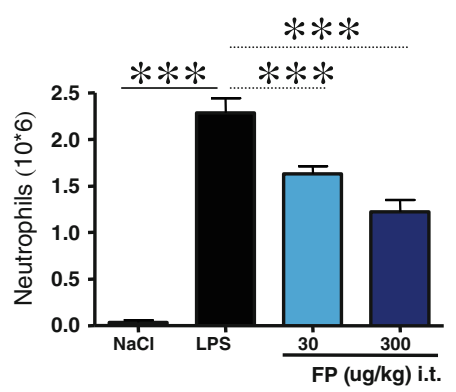

$* * P<0.01, * * * P<0.001$. b Sensitivity of LPS-induced inflammation to steroids. Four groups of BALB/c mice (8 mice per group) were exposed to air, LPS, LPS plus $30 \mu \mathrm{g} / \mathrm{kg}$ of FP, LPS plus $300 \mu \mathrm{g} / \mathrm{kg}$ FP. The cellular response in BAL is shown, reflecting total cells, macrophages and neutrophils. Statistically significant differences between groups are shown as $* P<0.05, * * P<0.01$, $* * * P<0.001$ 
Mice lacking the CCR1 receptor have a reduced inflammatory response to TS

We wished to further characterise the acute tobacco smoke model. Given we observed the CCR 1 ligand MIP- $1 \alpha$ in the BAL of animals after tobacco smoke exposure, we investigated the role of the MIP1 $\alpha$ receptor, CCR1, in the tobacco smoke model. We carried out a 4 day TS exposure on mice lacking the CCR1 gene (CCR1 Knock out) and compared this to wild type mice. It can be seen that the inflammatory response to TS is dramatically reduced in the CCR1 KO mice. This is observed by a reduction in neutrophils in the BAL (Fig. 4) as well as a reduction in IL-1B and MIP- $1 \alpha$ in the BAL (Fig. 4). The levels of $\mathrm{KC}$ in the CCR1 KO animals were not reduced but, in fact, elevated in the BAL of the transgenic mice.

\section{Discussion}

Novel anti-inflammatories are sought for the treatment of COPD. Mouse models are being increasingly used to understand smoke-induced inflammation [8] and are used within the pharmaceutical industry to support drug discovery programs. Many tobacco smoke models are run as chronic models, often with changes in lung structure measured by mean linear intercept of airspaces (for reviews, see $[9,10])$.

There are far fewer acute models of cigarette exposure, and it was our intention to develop a new acute model of TS-driven inflammation with some characteristics of smoke-induced inflammation in humans. We also think that the steroid insensitivity of the model is key and that compounds showing greater efficacy in the tobacco smoke model than steroids have a greater chance of efficacy in human clinical trials. The model is also of reasonable throughput and can be used for the medium throughput evaluation of candidate drugs for novel anti-inflammatories. In addition, we see it as a valuable platform for adding in extra factors to augment the effects of TS and for further understanding the pathobiology of smoke-induced inflammation.

Leclerc et al. [11] describe an acute TS model in which mice were exposed to TS for 3 days and a neutrophildominated response was seen, although this was also accompanied by significant eosinophilia. A full
A Total Cells

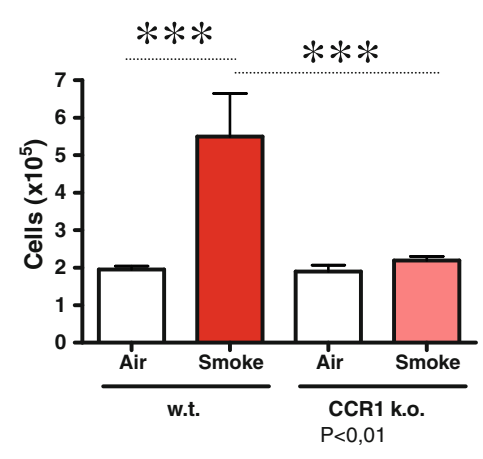

D KC

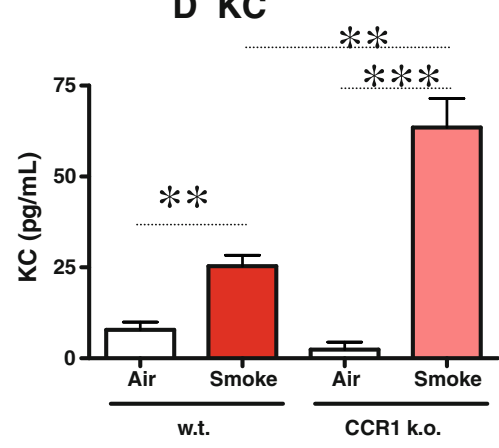

B Macrophages

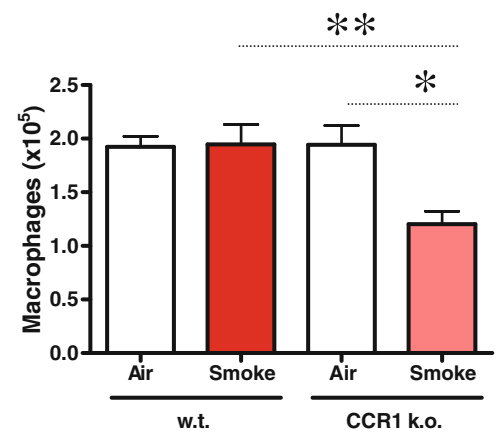

E MIP1

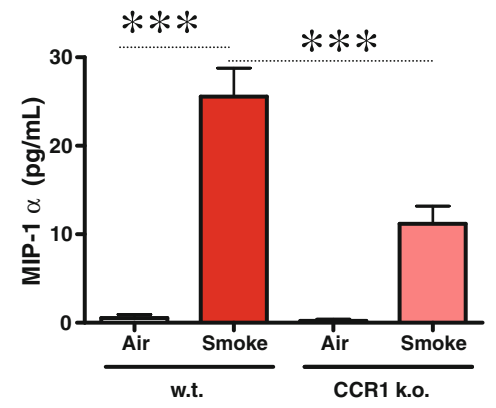

C Neutrophils

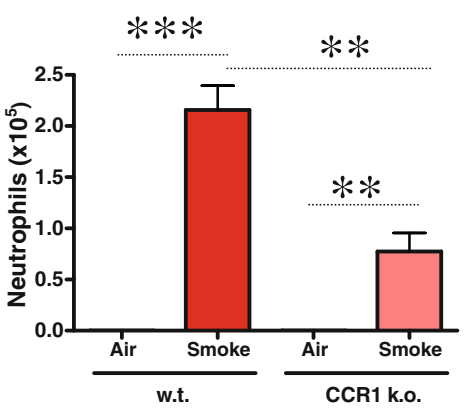

F IL-1B

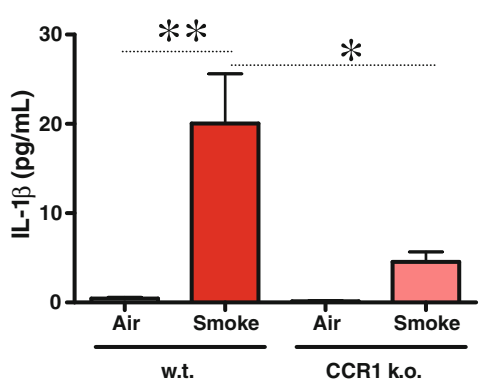

Fig. 4 Effects of deletion of the gene for the CCR1 receptor on TSinduced inflammation. Wild type female C57/BL76 mice ( 8 per group) or female CCR1 transgenic C57/BL76 mice (8 per group) were exposed to TS for 4 days for 50 min twice a day. Control groups were included that were exposed only to air. After 4 days the animals were terminated and the following determined. a Total cells within the BAL, b macrophages within the BAL, c neutrophil levels, d KC levels, e MIP-1 levels and f IL-1 beta levels. Air controls are shown as clear columns and smoke exposed groups as red columns. Statistically significant differences between groups are shown as $* P<0.05$, $* * P<0.01, * * * P<0.001$ 
characterisation of the inflammatory response was not done. However, KC, MIP-1 and MIP-2 were shown to be upregulated in the BAL. The model also showed a degree of steroid insensitivity, however the steroid tested was dexamethasone. In the present study, we used the much more potent steroid FP (versus the glucocorticoid receptor) [12]. In addition, at the highest concentration of dexamethasone tested, inflammation was reduced in the model described by Leclerc [11]. Medicherla et al. [13] have also described a tobacco smoke model. There, mice were exposed for 5 or 11 days and, in stark contrast to both our model and the model of Leclerc et al., an inflammatory influx was seen that was dominated by macrophages. Again, the inflammation seen was resistant to dexamethasone, but dose levels of only up to $0.3 \mathrm{mg} / \mathrm{kg}$ were used. The differences in inflammatory cell population between the model described by Medicherla et al., and the one reported here is interesting, but may merely reflect that in Medicherla et al., A/J mice were used, while we used $\mathrm{BALB} / \mathrm{c}$ mice. A/J mice lack part of the complement system [14] and perhaps would not be able to promote a full anti-inflammatory response to the TS challenge. In fact, many other studies assessing acute TS exposure in mice with fully intact complement systems show that acute TS exposure leads to an inflammatory infiltrate dominated by neutrophils $[15,16]$ and not by macrophages. Although COPD is a complex disease with a range of cellular and molecular pathologies, neutrophils are also common in COPD [17, 18].

In addition, a number of mediators observed specifically in the BAL after TS exposure are in common with mediators seen in humans exposed to cigarette smoke. MCP-1 is involved in the recruitment of monocytes, lymphocytes and basophils and a member of the CC chemokines [19]. Elevated expression of MCP-1 is seen in COPD [20]. MCP-1 levels also correlate with a decline in lung function in COPD [21]. Reduction of MCP-1 levels with a therapeutic antibody in COPD patients also serves to reduce neutrophil numbers [9]. IL-8, the human equivalent of $\mathrm{KC}$, is also increased in COPD [22] and this is reflected in the BAL samples from TS exposed animals. From the Rules Based Medicine analysis we can see that MMP-9 is one of the proteins highly up-regulated in TS-exposed animals compared to air-exposed animals. MMP-9 has been shown to be present within COPD lungs [23] and also to increase within a COPD exacerbation [24]. This could reflect the beginning of a protease/anti-protease imbalance within the model. The protease/anti-protease balance is one of the core themes around the pathology of COPD [25] and its imbalance may also contribute to further damage during a COPD exacerbation [24].

One interesting omission from the array of mediators present in the model is the lack of $\mathrm{TNF} \alpha$. TNF $\alpha$ is seen in the BAL of COPD patients [22]. The lack of TNF $\alpha$ may represent the mild nature and acute exposure times of the model. Other acute TS models, also, have not reported seeing $\mathrm{TNF} \alpha$ after acute TS exposure $[13,16]$, or report no increase after TS exposure [15].

Gene expression patterns in whole lung tissue following TS exposure changes dramatically. Many of the changes seen are related to oxidative stress and this has also been implicated in COPD [26]. The expression of genes related to oxidative stress in COPD has been studied in epithelial cells [27]. Genes involved in proteolytic processing were also increased. Specific genes such as Noxo1 were upregulated. Noxo1 is a regulator of NADPH oxidase and, presumably, its up-regulation indicates a response to TS in trying to control damage via the production of reactive oxygen species [28], but may subsequently also increase inflammation via the activation of NFkB and MAP kinase pathways [28]. CXCL5 was up-regulated in the TS exposed mice after 4 days and has also been shown to be up-regulated in COPD [29]. MMP-12 is also up-regulated within COPD patients [30].

Overall, the characterisation of the TS exposed mice reveals a number of similarities to tobacco smoke exposure in humans, even after acute exposure. Pharmacological intervention studies will enable resolution as to which markers are affected by treatment and thus allow comparison between different anti-inflammatory mechanisms.

We feel a key feature of the TS model is that the inflammation observed, as measured by the influx of neutrophils to the lung, is relatively steroid insensitive compared to that seen in an LPS-driven mouse inflammatory model (Fig. 3). Although we used Pseudomonas LPS, the same effects and steroid sensitivity were seen from experiments with Escherichia coli LPS (data not shown). We do not think that this insensitivity to steroids is caused by the "volume" of the inflammation. The levels of neutrophilia driven by LPS are higher than by TS (Fig. 3). We hypothesise that the TS exposure triggers molecular switches in vivo. This switching affects the pharmacological intervention by a steroid in the TS model.

Steroids work in COPD but the inflammation is not as well controlled as in asthma [31]. FP is ineffective at controlling neutrophils in COPD [32] and therefore there is a pharmacological link between the TS exposure model and human disease. Interestingly, FP is able to reduce LPSdriven neutrophilia in humans $6 \mathrm{~h}$ after LPS challenge [33], which again correlates to the ability of FP to reduce LPSdriven neutrophilia in mice. We are currently assessing other differences in endpoints between LPS- and TS-driven models to assess whether further insights can gained for steroid efficacy in reducing smoke- or LPS-induced inflammation. Also, we will use the TS exposure model in the future in assessing other pharmacological mechanisms 
with greater potential than steroids in reducing inflammation provoked by tobacco smoke.

Having established the TS exposure model and characterised it with known agents in respiratory disease, we have begun to use it to test the rationale for other mechanisms as potential targets within COPD. One such hypothesis was of the role of CCR1 in regulating TS-induced inflammation; the CCR1 ligand was observed in the BAL of smokeexposed animals. The chemokine receptor CCR1 belongs to the seven-transmembrane $G$ protein coupled receptor (GPCR) super-family of receptors and is expressed primarily by $\mathrm{T}$ lymphocytes, monocytes/macrophages, basophils, dendritic cells, eosinophils and neutrophils. CCR1 deficient mice have been generated, and they show normal development and leukocyte profiles, but significantly reduced leukocyte mobilization in response to different inflammatory stimuli [34]. A number of compounds against this receptor are in development for the treatment of autoimmune/inflammatory diseases [35].

Exposure of mice lacking the CCR1 receptor to TS showed a significantly reduced inflammatory response compared to wild type mice. As well as showing a reduced neutrophil response, the levels of IL- 1 and MIP- $1 \alpha$ in the BAL following TS exposure were lower in CCR1 deficient mice than in wild type controls. This suggests that blockade of the CCR1 receptor may be a therapeutic strategy for the treatment of tobacco smoke-driven inflammation. There is some evidence from human studies to support this statement. Increased frequency of MIP- $1 \alpha$ positive epithelial cells in the bronchial mucosa was observed in COPD patients, and the frequency of MIP- $1 \alpha$ expressing cells correlated with reduced lung function $\left(\mathrm{FEV}_{1}\right)$ [36]. Key CCR1 ligands (MIP-1 $\alpha$, RANTES and MCP-3) have been found to be expressed in COPD lung tissue and are present in BAL or sputum from COPD patients [37].

Within the CCR1 deficient mice study, it was interesting that after TS exposure the levels of $\mathrm{KC}$, the mouse homologue of IL-8, were not reduced in the same fashion as other markers, but in fact were increased after TS exposure compared to wild type controls. Perhaps this reflects a compensation response, more KC (IL-8) being produced as a chemotactic factor to try and draw neutrophils into the lung. We can also postulate that this means that there may be other factors, independent of KC (IL-8), that are responsible for the recruitment of neutrophils into the lung. This has been suggested for COPD, specifically that neutrophils in COPD patients show reduced levels of migration and chemotaxis in response to IL-8 [38].

Mice insufficient in CCR1 have been analysed previously in separate model systems. The same transgenic animals have been used in separate studies published elsewhere by others. Pancreatitis associated lung injury is CCR1 dependent [39]. In addition, leukocyte recruitment is dependent on CCR1 in allergic encephalomyelitis models [40]. The deletion of CCR1 reduces responses following RSV infection [41].

In summary, we have developed an acute tobacco smokedriven mouse model of inflammation. It has many similarities to inflammation seen in humans exposed to tobacco smoke. We intend to use the model to further explore the pharmacology of TS-induced inflammation, to attempt to build the predictivity of the model for predicting efficacy of antiinflammatories in humans and to assess the mechanisms responsible for steroid insensitivity in vivo. As the model is relatively simple, robust and of reasonable throughput we also feel it can be a platform for the exploration of other factors involved in smoke-induced inflammation, for example, the addition of virus or bacteria to TS-induced inflammation [6]. We have explored the role of the CCR1 receptor in TS-induced inflammation and we find that ablation of this gene significantly reduces TS-driven neutrophilia.

Acknowledgments This work was supported by AstraZeneca.

Conflict of interest statement Per-Ola Önnervik, Maria Lindahl, Naila Svitacheva, Kerstin Thim, Amir Smailagic, Robert Virtala \& John D. Taylor are all employees of AstraZeneca.

Open Access This article is distributed under the terms of the Creative Commons Attribution Noncommercial License which permits any noncommercial use, distribution, and reproduction in any medium, provided the original author(s) and source are credited.

\section{References}

1. Vigei G, Pistelli F, Sherill DL, Maio S, Baldicci S, Carrozzi L. Definition, epidemiology and natural history of COPD. Eur Respir J. 2007;30:993-1013.

2. O'Byrne PM. Exacerbation of asthma \& COPD: definitions, clinical manifestations \& epidemiology. In: Sjöbring U, Taylor JD, editors. Models of exacerbations in asthma \& COPD: contributions to microbiology, vol. 14. Karger: Basel; 2007. p. 1-11.

3. Rodriguez-Roisin R. Toward a consensus definition or COPD exacerbation. Chest. 2000;117(5 Suppl 2):398S-401S.

4. Burge S, Wedzicha JA. COPD exacerbations: definitions and classifications. Eur Respir J. 2003;41:46s-53s.

5. Wedzicha JA, Seemungal T. COPD exacerbations: defining their cause and prevention. Lancet. 2007;370:786-96.

6. Gashler GJ, Skrtic M, Zavitz CCJ, Lindahl M, Önnervik PO, Murphy TF, Sethi S, Stampfli MR. Bacteria challenge in smoke exposed mice exacerbates inflammation and skews the inflammatory profile. Am J Respir Crit Care Med. 2009. doi: 10.1164/rccm.200808-1306OC.

7. Broberg P. Statistical methods for ranking differentially expressed genes. Genome Biol. 2003;4:R41.

8. Shapiro S, DeMeo D, Silverman EK. Smoke and mirrors. Mouse models as a reflection of human chronic obstructive pulmonary disease. Am J Respir Crit Care. 2004;170:929-31.

9. Fitzgerald MF, Cox CJ. Emerging trends in the therapy of COPD: novel anti-inflammatory agents in clinical development. Drug Discov Today. 2007;12:479-86. 
10. Churg A, Wright J. Animal models of cigarette smoke-induced COPD. In: Sjöbring U, Taylor JD, editors. Models of exacerbations in asthma \& COPD: contributions to microbiology, vol. 14. Karger: Basel; 2007. p. 113-25.

11. Leclerc G, Lagente V, Planquis JM, Berthelier C, Artola M, Eicholtz T, et al. Involvement of MMP-12 and PDE4 in cigarette smoke-induced inflammation in mice. Eur Respir J. 2006;27: 1102-9.

12. Biggadike K, Bledsoe R, Hassell A, Kirk B, McLay IM, Shewchuk L, et al. X-ray crystal of the novel enhanced affinity agonist fluticasone furoate in the gluticocorticoid receptor ligand domain. J Med Chem. 2008;51(12):3349-52.

13. Medicherla S, Fitzgerald M, Spicer D, Woodman P, Ma J, Kapoun A, et al. p38-a Selective mitogen activated protein kinase inhibitor SD-282 reduced inflammation in a subchronic model of TS induced airway inflammation. J Pharmacol Exp Ther. 2008;324:921-9.

14. Amano MT, Carneiro AS, Ribeiro OG, Cabrera WK, De Franco M, Ibanez OM, et al. A new model of outbred genetically selected mice which present a strong acute inflammatory response in the absence of complement C5. Inflamm Res. 2009;58:204-9.

15. Thatcher T, McHugh N, Egan R, Chapman R, Hey JA, Turner C, et al. Role of CXCR2 in cigarette smoke-induced lung inflammation. Am J Physiol Lung Cell Mol Physiol. 2005;289:L322-8.

16. Sato A, Hoshino Y, Hara T, Muro S, Nakamura H, Mishima M, et al. Thioredoxin-1 ameliorates cigarette smoke-induced lung inflammation and emphysema in mice. J Pharmacol Exp Ther. 2008;325:380-8.

17. Thompson AB, Daughton D, Robbins RA, Ghafouri MA, Oehlerking M, Rennard SI. Intraluminal airway inflammation in chronic bronchitis. Characterisation and correlation with clinical parameters. Am Rev Respir Dis. 1989;140(6):1527-37.

18. Lacoste JY, Bousquet J, Chanez P, Van Vyve T, SimonyLafontaine $\mathrm{J}$, Lequeu $\mathrm{N}$, et al. Eosinophilic inflammation in asthma, chronic bronchitis and COPD. J Allergy Clin Immunol. 1993;92(4):537-48.

19. Chung KF. Cytokines in chronic obstructive pulmonary disease. Eur Respir J Suppl. 2001;34:50s-9s.

20. DeBoer WI, Sont JK, van Schadewwijk A, Stolk J, van Krieken JH, Hiemstra PS. Monocyte chemoattractant protein 1, interleukin 8 and chronic airways inflammation in COPD. J Pathol. 2000;190:619-26.

21. Traves SL, Culpitt SV, Russell RE, Barnes PJ, Donnelly LE. Increased levels of the chemokines GROalpha and MCP-1 in sputum samples from patients with COPD. Thorax. 2002;57(7): $590-5$.

22. Keatings VM, Collins PD, Scott DM, Barnes PJ. Differences in interleukin-8 and tumour necrosis factor-alpha in induced sputum from patients with chronic obstructive pulmonary disease or asthma. Am J Respir Crit Care Med. 1996;153(2):530-4.

23. Boschetto P, Quintavalle S, Zeni E, Leprotti S, Potena A, Ballerin $\mathrm{L}$, et al. Associated between markers of emphysema and more severe chronic obstructive pulmonary disease. Thorax. 2006;61: 1037-42.

24. Mercer PF, Shute JK, Bhomik A, Donaldson GC, Wedzicha JA, Warner JA. MMP-9, TIMP-1 and inflammatory cells in sputum from COPD patients during exacerbations. Respir Res. 2005;6(19): 151.

25. Hogg JC, Senior RM. Chronic obstructive pulmonary disease-2; pathology and biochemistry of emphysema. Thorax. 2002;57: $830-4$.
26. Macnee W. Update in chronic obstructive pulmonary disease 2007. Am J Respir Crit Care Med. 2008;177(8):820-9.

27. Pierrou S, Broberg P, O’Donnell R, Pawlowski K, Virtala R, Lindqvist $\mathrm{E}$, et al. Expression of genes involved in oxidative stress responses in airway epithelial cells of smokers with chronic obstructive pulmonary disease. Am J Respir Crit Care Med. 2007;175:577-86.

28. Yao H, Yang S, Kode S, Rajendrasozhan S, Caito S, Adenuga D, et al. Redox regulation of lung inflammation: role of NADPH oxidase and NF-kappaB signalling. Biochem Soc Trans. 2007;35: 1151-5.

29. Qiu Y, Zhu J, Bandi V, Atmar R, Hattotuwa K, Guntupalli K, et al. Biopsy neutrophilia, neutrophil chemokine and receptor gene expression in severe exacerbations of COPD. Am J Respir Crit Care Med. 2003;168:968-75.

30. Molet S, Belleguic C, Lena H, Germain N, Bertrand CP, Shapiro $\mathrm{SD}$, et al. Increase in macrophage elastase from patients with COPD. Inflamm Res. 2005;54:31-6.

31. Yang IA, Fong KM, Sim EH, Black PN, Lasserson TJ. Inhaled corticosteroids for stable chronic obstructive pulmonary disease. Cochrane Database Syst Rev. 2007;18:CD002991.

32. Culpitt S, Maziak W, Loukidis S, Nightingale J, Matthews J, Barnes PJ. Effect of high dose inhaled steroid on cells, cytokines, and proteases in induced sputum in chronic obstructive pulmonary disease. Am J Respir Crit Care Med. 1999;160:1635-9.

33. Alexis N, Peden D. Blunting airway eosinophilic inflammation results in a decreased airway neutrophil response to inhaled LPS in patients with atopic asthma: a role for CD14. J Allergy Clin Immunol. 2001;108:577-80.

34. Gao JL, Wynn TA, Chang Y, Lee EJ, Broxmeyer HE, Cooper S, et al. Impaired host defense, hematopoiesis, granulomatous inflammation and type 1-type 2 cytokine balance in mice lacking CC chemokine receptor 1. J Exp Med. 1997;185:1959-68.

35. Gladhue R, Zwillich S, Clucas A, Brown M. CCR1 antagonists for the treatment of autoimmune diseases. Curr Opin Investig Drugs. 2004;5:499-504.

36. Di Stefano A, Capelli A, Lusuardi M, Balbo P, Vecchio C, Maestrelli $\mathrm{P}$, et al. Severity of airflow limitation is associated with severity of airway inflammation in smokers. Am J Respir Crit Care Med. 1998;58:1277-85.

37. Fujimoto K, Yasuo M, Urushibata K, Hanaoka M, Koizumi T, Kubo K. Airway inflammation during stable and acutely exacerbated chronic obstructive pulmonary disease. Eur Respir J. 2005;25:640-6.

38. Yoshikawa T, Dent G, Ward J, Angco G, Nong G, Nomura N, et al. Impaired neutrophil chemotaxis in chronic obstructive pulmonary disease. Am J Respir Crit Care Med. 2007;175:473-9.

39. Gerard C, Frossard JL, Bhatia M, Saluja A, Gerard NP, Lu B, et al. Targeted disruption of the chemokine receptor CCR1 protects against pancreatitis associated lung injury. J Clin Investig. 1997;8:2022-7.

40. Rottman J, Slavin A, Silva R, Weiner H, Gerard C, Hancock W. Leukocyte recruitment during onset of allergic encephalomyelitis is CCR1 dependent. Eur J Immunol. 2000;30:2372-7.

41. Miller A, Gerard C, Schaller M, Gruber A, Humbles A, Lukas N. Deletion of CCR1 attenuates pathophysiologic responses during respiratory syncytial virus infection. J Immunol. 2006;176: 2562-7. 